\title{
Aging partially restores the efficacy of malaria vector control in insecticide-resistant populations of Anopheles gambiae s.l. from Burkina Faso
}

\author{
Christopher M Jones ${ }^{1 *}$, Antoine Sanou ${ }^{2}$, Wamdaogo M Guelbeogo ${ }^{2}$, N'Fale Sagnon², Paul CD Johnson ${ }^{3}$ and \\ Hilary Ranson ${ }^{1}$
}

\begin{abstract}
Background: The operational impact of insecticide resistance on the effectiveness of long-lasting insecticide nets (LLINs) and indoor residual spraying (IRS) is poorly understood. One factor which may prolong the effectiveness of these tools in the field is the increase in insecticide susceptibility with mosquito age. In this study, LLINs and IRS were tested against young (three to five days) and old (17-19 days) pyrethroid resistant Anopheles gambiae s.l. from Burkina Faso.

Methods: Blood-fed adult Anopheles gambiae s.l. were collected from south-west Burkina Faso and identified to species/form level. Cohorts of the F1 progeny of An. gambiae s.s. S-forms were exposed to deltamethrin (0.05\%) at three to five or 17-19 days post-emergence and tested for the frequency of the resistance allele 1014F. Isofemale lines of the M, S- form of An. gambiae s.S. and Anopheles arabiensis were exposed in WHO cone tests to either a) LLINs deployed in households for two years or (b) bendiocarb sprayed walls.

Results: Mortality rates in response to deltamethrin (0.05\%) increased from levels indicative of strong resistance in three to five day old F1 mosquitoes, to near full susceptibility in the 17-19 day old cohort. On exposure to LLINs sampled from the field, the mortality rate in isofemale lines was higher in older mosquitoes than young $(\mathrm{OR}=$ $5.28, \mathrm{Cl} 95 \%=2.81-9.92)$, although the mortality estimates were affected by the LLIN tested. In general, the LLINs sampled from the field performed poorly in WHO cone bioassays using either laboratory susceptible or field caught mosquito populations. Finally, there was a clear relationship between mortality and age on exposure to bendiocarb-sprayed walls, with older mosquitoes again proving more susceptible $(\mathrm{OR}=3.39, \mathrm{Cl} 95 \%=2.35-4.90)$.

Conclusions: Age is a key factor determining the susceptibility of mosquitoes to insecticides, not only in laboratory studies, but in response to field-based vector control interventions. This has important implications for understanding the epidemiological impact of resistance. If mosquitoes old enough to transmit malaria are still being suppressed with available insecticides, is resistance potentially having less of an impact than often assumed? However, the poor performance of LLINs used in this study in Burkina Faso, is a cause for concern and requires urgent investigation.
\end{abstract}

\section{Background}

Long-lasting insecticide nets (LLINs) and indoor residual spraying (IRS) have set a benchmark in malaria prevention. Significant reductions in malaria burden and transmission have been reported using LLINs and IRS alone or in combination [1-3]. In a bid to achieve the

\footnotetext{
* Correspondence: jonescm@liverpool.ac.uk

'Liverpool School of Tropical Medicine, Pembroke Place, Liverpool L3 5QA, UK

Full list of author information is available at the end of the article
}

longer term goal of elimination, National Malaria Control Programmes (NMCP), donors and global health initiatives are fervently scaling up deployment of these interventions across Africa [4,5]. In Burkina Faso for example, the NMCP has procured approximately eight million LLINs to ensure widespread coverage in malaria endemic areas in 2010 [6].

It is against this backdrop that the emergence of insecticide resistance in the major African malaria vectors (Anopheles gambiae s.s., Anopheles arabiensis and
C Biomed Central

C 2012 Jones et al; licensee BioMed Central Ltd. This is an Open Access article distributed under the terms of the Creative Commons Attribution License (http://creativecommons.org/licenses/by/2.0), which permits unrestricted use, distribution, and reproduction in any medium, provided the original work is properly cited. 
Anopheles funestus) represents a serious concern. The arsenal of insecticides available for public health is limited to only four classes of chemistry (pyrethroids, organophosphates, carbamates and the organochlorine DDT) with no further additions on the market since the 1970s. Pyrethroids remain the only insecticide available for LLINs; resistance to this class has developed in the major vectors and is now firmly established throughout Africa [7-10]. Although carbamates and organophosphates offer a promising solution to counter pyrethroid resistant mosquitoes $[11,12]$, pockets of resistance to these insecticides are emerging in West Africa [13,14]. The urgent need for alternative insecticides in disease control has been recognized for some time $[15,16]$, however it is only lately that strides in addressing this issue have been made [17].

Insecticide resistance in An. gambiae s.s. is tightly linked to the ecology and agricultural practices of Burkina Faso. A large cotton belt extends from the west of the country towards the south and it is here that a resistance management strategy based on the rotation of pyrethroids, carbamates/organophosphates and organochlorines has been adopted since the 1990s to prevent extensive damage from cotton insect pests [14]. In recent years, the area of cultivation and volume of insecticide sprayed to protect cotton yields has increased dramatically and as a result, the levels of pyrethroid and DDT resistance in An. gambiae s.s. from this part of the country are much greater than in the central and eastern areas $[18,19]$. Resistance to a carbamate (bendiocarb) and an organophosphate (fenitrothion) has been detected from the same region [20]. These observed resistance patterns are closely related to the relative frequency and distribution of both the An. gambiae s.s. species complex and target-site mutations associated with insecticide resistance. The S-molecular form of $A n$. gambiae s.s. predominates throughout the cotton belt regions of the south-west. The sodium channel mutation L1014F (otherwise known as knockdown resistance, $k d r$ ) and the acetylcholinesterase mutation G119S (ace-1), which reduce sensitivity to pyrethroids/DDT and organophosphates/carbamates respectively, are both found in S-form An. gambiae s.s. of the cotton belt region of Burkina Faso. Here, the $k d r$ allele is approaching fixation in the $\mathrm{S}$-form and, in Soumousso, is at approximately 0.6 in the M-form (N'Fale et al. unpublished data). In contrast, An. arabiensis from the cotton belt remains largely susceptible to pyrethroids.

In an area of insecticide resistance, it is anticipated that the number of mosquitoes surviving LLINs and/or IRS will rise and, as a result, the ability of the local vector population to transmit disease will increase. The relationship between insecticide resistance and vectorial capacity is, however, poorly understood. Relationships between insecticide resistance and insect fitness, longevity, behaviour and parasite interactions may increase or, indeed, decrease the vectorial capacity of mosquitoes (reviewed by Rivero et al. [21]). One recently revisited aspect of this relationship is the decline in insecticide resistance observed with increasing mosquito age. Mosquitoes, which would otherwise be defined as 'resistant' according to the standard WHO susceptibility tests, gradually lose their tolerance to insecticides as they become older and this has been demonstrated in multiple species [22-27]. The very success of LLINs and IRS is based on their ability to reduce the daily survival rate of the Anopheles vector and prevent the completion of parasite development into the infectious sporozoite stage. If resistance declines in older mosquitoes, it may be expected that those insects which have lived long enough to become infectious, on entering a house, have a far greater chance of being killed on encountering either an LLIN or a sprayed wall. In this scenario, the intervention would continue to provide a continued degree of efficacy even in the presence of multiple insecticide resistance mechanisms. The reduced phenotypic resistance in older mosquitoes has been tested in several laboratory studies [25-27], but very few studies have explored this trait in natural populations. Furthermore, the impact of this on the effectiveness of vector control tools under field conditions is largely unexplored. The objective of this study was to determine whether insecticide-based malaria control activities remain effective against both young and old An. gambiae s.s. collected from an area of strong resistance in south-west Burkina Faso.

\section{Methods}

\section{Study site and mosquito collections}

Blood-fed female Anopheles gambiae were collected between 0700 and $0900 \mathrm{~h}$ from the inside of houses from the village of Soumousso, located in the southwest of Burkina Faso (N $11^{\circ} 00^{\prime} 46^{\prime \prime}, \mathrm{W} 04^{\circ} 03^{\prime} 25^{\prime \prime}$ ). A total of six collections were undertaken during August to November 2010. Soumousso lies within the heart of a large cotton-growing region where crops such as maize and rice are also grown. For control of agricultural pests, insecticides are sprayed up to six times per year between June and October and rotated among pyrethroids, organophosphates and carbamates. Routine insecticide resistance monitoring has been performed in this area since 2008 as part of a WHO/TDR multi-country project and resistance to all major insecticide classes available for malaria control has been reported [20]. No centrally organized malaria control is conducted in this region and insecticide treated net usage is low. The predominant An. gambiae s.s. sub-species found in Soumousso during the early part of the malaria 
transmission season is An. gambiae s.s. S-molecular form, whereas the number of An. gambiae s.s. M-form and $A n$. arabiensis increases towards the end of the rainy season [20].

\section{Mosquito rearing and species identification}

All mosquitoes were reared in the insectaries at the Centre National de Recherche et de Formation sur le Paludisme (CNRFP), Ouagadougou. Blood-fed female An. gambiae were placed individually in small cups for oviposition over a two to four-day period. Immediately after egg-lay, a single leg was removed from each F0 female parent and used directly for species identification following SINE-PCR which discriminates between Sform, M-form and An. arabiensis [28]. Mosquitoes which failed to lay eggs or could not be identified to species were removed from the study. Eggs and newly hatched larvae from each individual parent were then either pooled according to species status or raised separately as isofemale lines. Adult mosquitoes were provided with a sugar solution for feeding. Blood meals were provided to mosquitoes older than five days. Mosquitoes that constituted the older cohort (17-19 days old) used in the study had received two blood meals and completed at least two gonotrophic cycles.

\section{Deltamethrin susceptibility tests}

In order to demonstrate an age-effect in the progeny of field caught mosquitoes, a minimum of 100 three to five-day and 17-19-day old female mosquitoes from each of two pooled S-form populations were exposed to WHO $0.05 \%$ deltamethrin impregnated papers for one hour. Only An. gambiae s.s. S-forms were used as this was the predominant species during the study period. The number of mosquitoes 'knocked down' was recorded at the end of exposure and mortality scored 24 $\mathrm{h}$ after. Control assays were performed throughout the experiment with a minimum of 25 mosquitoes exposed to non-insecticide treated papers.

\section{L1014F TaqMan assay}

Genomic DNA (gDNA) was extracted from 12 An. gambiae s.s. S-form mosquitoes either exposed to deltamethrin $(0.05 \%)$ or from the control assays (non-exposed). One percent of the total gDNA was used in a TaqMan allelic discrimination PCR described by Bass et al. [29] to detect the presence of the $1014 F k d r$ allele

\section{Long-lasting insecticide net assays}

Three Permanet2.0 ${ }^{\circledR}$ LLINs were sampled from the village of Laye situated $35 \mathrm{~km}$ north-west of the capital Ouagadougou (N $\left.12^{\circ} 31^{\prime} 35^{\prime \prime}, \mathrm{W} 1^{\circ} 46^{\prime} 21^{\prime \prime}\right)$. The nets had been deployed in the village for approximately 2 years prior to the study as part of the Burkina Faso
NMCP and were exchanged for new LLINs with the householder upon retrieval. Cohorts of three to fiveand 17-19-day old mosquitoes from individual isofemale lines were exposed to each LLIN in WHO cone assays. Batches of five mosquitoes from the two age-cohorts belonging to the same isofemale line were exposed to the same piece of LLIN for 3 minutes according to WHO guidelines [30]. Only isofemale lines, which produced more than 20 female adults were selected for testing to ensure sufficient numbers were available for bioassays on each age cohort. Knockdown was recorded 1 hour following exposure and mortality scored $24 \mathrm{~h}$ later.

\section{LLIN evaluation}

The LLINs were transported to the Liverpool School of Tropical Medicine (LSTM) to assess the insecticidal properties of the nets. A minimum of 24 females from a laboratory susceptible An. gambiae strain (Kisumu) were exposed for 3 minutes in WHO cone assays against each LLIN and mortality recorded $24 \mathrm{~h}$ later.

An estimate of the concentration of deltamethrin on each net was performed using HPLC. For each net, five random samples ( $30 \mathrm{~mm}$ in diameter) were cut from different areas of the net (total area of $35.5 \mathrm{~cm}^{2}$ ). The five pieces were cut into smaller pieces into a $50 \mathrm{ml}$ Falcon tube, $40 \mu \mathrm{l}$ of DDT $2 \mathrm{mg} / \mathrm{m}^{2}$ was added as an internal standard (normalise extraction), and acetone extracted by vortexing $3 \times$ with $5 \mathrm{ml}$ acetone, pooled and evaporated to dryness under a stream of nitrogen. The insecticide residue was recovered in $1 \mathrm{ml}$ acetonitrile and filtered with a $17 \mathrm{~mm}$ PTFE $0.2 \mu \mathrm{m}$ syringe filter (Chromacol LTD, UK) before analysis. HPLC analysis was performed by injection of $20 \mu \mathrm{l}$ aliquots onto a reverse-phase Dionex Acclaim C18 column (120Á, $250 \times 4.6 \mathrm{~mm}, 5 \mu$, Dionex, Camberley, UK). A mobile phase of methanol/water 90:10 was used at a flow rate of $1 \mathrm{ml} / \mathrm{min}^{-1}$.

The quantity of deltamethrin remaining on the net $\left(\mathrm{mg} / \mathrm{m}^{2}\right)$ was calculated from the standard curve established with known concentrations of an authenticated deltamethrin peak detected using an Ultimate 3000 UV detector and analysed with Dionex Chromeleon software.

\section{Bendiocarb IRS assays}

Three houses from the village of Laye were sprayed with bendiocarb $\left(200 \mathrm{mg} / \mathrm{m}^{2}\right)$ on 27 August, 2010 using Hudson sprayers. Two houses were composed of mud walls and one built of cement. Between three and 8 weeks later, approximately 10 mosquitoes from each age cohort from each isofemale line described above were exposed to the bendiocarb sprayed wall for $3 \mathrm{~min}$ using WHO cone tests. A maximum of five mosquitoes were 
used per cone (two cones) and knockdown and mortality were recorded as described above. The same area of each wall was used to test the different age groups from the same isofemale line. Mosquitoes from both age groups were exposed to a non-sprayed wall in a different house as a control throughout all bioassays.

The above 3 min exposure experiment was designed to maximise the chances of observing age related changes in mortality. However, as the WHO protocol for evaluating IRS involves a $30 \mathrm{~min}$ exposure, we repeated the experiment in May 2011. Three houses were sprayed as described above and mosquitoes collected from Soumousso were used for the bioassays. The only difference in methodology was that mosquitoes were exposed to the surfaces for $30 \mathrm{~min}$, as opposed to 3 min.

\section{Statistical analysis}

The exact $95 \%$ confidence intervals for mortality in bioassays were calculated according to the Binomial distribution using $\mathrm{R}$ version 2.12.2 for Windows [31]. A Fisher exact test $(p<0.05)$ was used to assess the statistical significance of differences in mortality between age groups.

Mortality from the LLIN and IRS isofemale experiments was modelled using binomial generalized linear mixed models (GLMM) with a logit link function in the $\mathrm{R}$ package "lme4" [32]. A separate model was derived for each experiment with the aim of estimating whether age had an effect on mosquito mortality (binary response variable) upon exposure to either a LLIN or a wall sprayed with bendiocarb. Mortality was primarily modelled as a function of three fixed factors; 'Age' (young (three to five days) or old (17-19 days)), 'Species' (An. arabiensis, An. gambiae s.s. S-form or An. gambiae s.s. M-form) and 'Treatment' (LLIN or sprayed wall labelled T1-T3). Furthermore, in both models, 'Family' was included as a random effect to allow the log odds of mortality to vary between families. Testing for interactions between categorical explanatory variables is problematic when there are zero frequencies within the contingency table (i.e. zero mortality within a subgroup). This results in parameter estimates whose likelihoods increase towards \pm infinity so that maximum likelihood estimates do not exist [33]. For this reason, and to test for evidence of possible interactions, a small weighted constant (total $=0.5$ ) was added to the mortality rates contributing to the zero cell count (no mortality) in the younger age-group exposed to LLIN\#1 [33]. Akaike's Information Criterion (AIC) was used to provide a strength of evidence for each model tested [34]. The estimated odds ratio with $95 \%$ confidence intervals was calculated relevant to the control treatment. More detail on the modelling approaches can be found in Additional file 1. All GLMM analyses were performed in $\mathrm{R}$ version 2.12.2 for Windows [31]. The R-script is available from the author on request.

\section{Results}

\section{Mosquito collections from Soumousso}

A total of 582 blood-fed Anopheles gambiae s.l. were collected from Soumousso and identified to species. $A n$. gambiae s.s. S-form pre-dominated throughout all collections. Between August and September over $73 \%$ of all $A n$. gambiae s.s. identified were An. gambiae s.s. S-form. The proportion of An. arabiensis and An. gambiae s.s. Mform was higher in October and November (Figure 1).

\section{Deltamethrin susceptibility tests}

Pools of $A n$. gambiae s.s. S-form from approximately 50 families were exposed to deltamethrin $(0.05 \%)$ in WHO susceptibility tests. This was repeated on two separate occasions (Assay 1 and Assay 2). In each experiment two age cohorts were exposed. The percentage mortality in three to five-day old mosquitoes ranged from $28.2 \%$ $(\mathrm{N}=103,19.7-37.9 \%)$ to $56.1 \%(\mathrm{~N}=107,46.2-65.7 \%)$. Mortality significantly increased in the 17-19-day old mosquitoes for both experiments $(p<0.0001)$ reaching 97.1\% $(\mathrm{N}=104,91.8-99.4 \%)$ and $98.1 \%(\mathrm{~N}=106,93.4-$ 99.8\%) (Figure 2). The percentage knockdown after 60 min exposure was high throughout all testing (between 92.4 to $100 \%$ ) and did not differ between the agecohorts. No control mortality was observed throughout the experiment. This experiment on pooled mosquitoes was performed to confirm that the age dependent resistance we had observed in earlier laboratory studies [25] was reproduced on field populations. The numbers of M-form and An. arabiensis were too low to repeat this experiment using these species/forms.

A sub-sample of 17-19-day old S-form An. gambiae s. $s$. was analysed for the $1014 F k d r$ allele from individuals dead following deltamethrin exposure and from nonexposed mosquitoes from the control bioassay. The frequency of $1014 F$ was $95.8 \%$ in both the test and control samples $(\mathrm{N}=12$ for each test). The high frequency of $1014 F$, supplemented by recent data collected from Soumousso as part of the WHO/TDR project, suggests that $1014 F$ is at a very high frequency in this population and therefore variation in $1014 \mathrm{~F}$ frequency is unlikely to contribute to the differences in mortality seen here between age-groups.

\section{Long-lasting insecticide net assays}

A total of 28 isofemale An. gambiae s.s. families from Soumousso (12 S-form, $11 \mathrm{M}$-form and five $A n$. arabiensis) were exposed to LLINs at three to five days and 


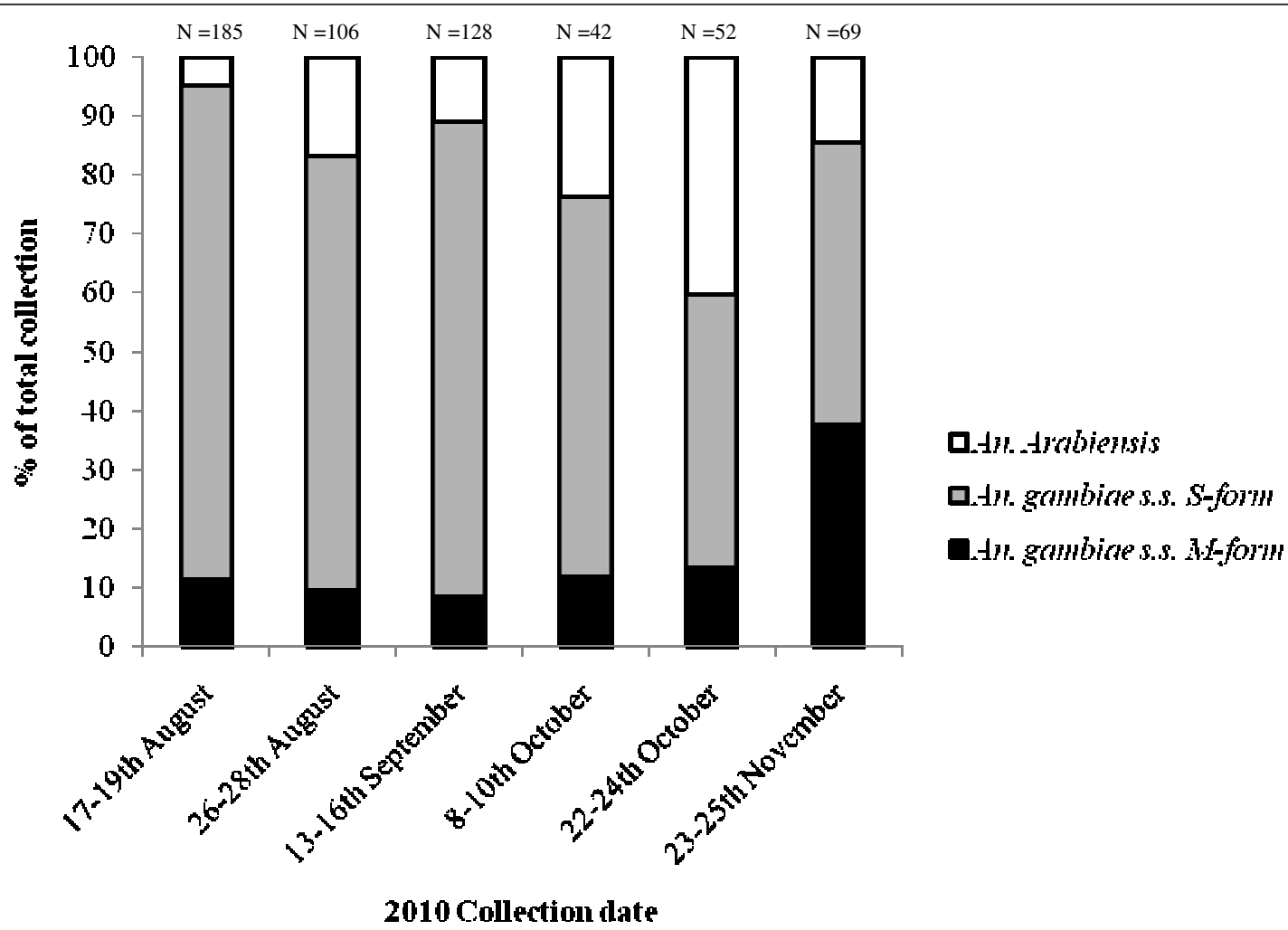

Figure 1 The relative percentage of Anopheles gambiae s.l. caught during 2010 from Soumousso in south-west Burkina Faso. F0 female An. gambiae s.s. caught from Soumousso were identified from each collection as An. gambiae s.s. M/S molecular form or An. arabiensis using SINE PCR [26]. The number identified from each collection is stated above the bar.

17-19 days old. The total number of mosquitoes exposed to each net and the number dead per isofemale are presented in Table 1.

The mortality of the isofemale An. gambiae s.s. from Soumousso varied between each of the LLINs used in the experiment and on the whole, the performance of the nets was poor. A boxplot showing the range of mortality within isofemale lines for each age cohort exposed to LLINs is given in Figure 3. All 12 of the isofemale lines tested on LLIN\#1, and seven out of nine on LLIN\#3, gave zero mortality when tested against the younger cohort (Figure 3). Against 17-19-day old mosquitoes, the performance was slightly better, with mortality ranging from 0 $55.5 \%$ for LLIN\#1 and 0-14.2\% for LLIN\#3. LLIN\#2 performed better,, but even with this net, mortality rates ranged from $87.5 \%$ at best, to $0 \%$ at worst, against three to five-day old mosquitoes. The performance of each LLIN from the field was reflected in the mortality rates of the laboratory susceptible colony (Table 2). The concentration of deltamethrin on each of the nets varied between $1.0-2.0 \mathrm{mg} / \mathrm{m}^{2}$ and is considerably lower than the original concentration on the net $\left(55 \mathrm{mg} / \mathrm{m}^{2}\right)$.

The relationship between age and resistance was not expected to differ between members of the An. gambiae complex and hence isofemale lines were not assigned to individual nets according to species. However, post hoc analysis did not indicate any evidence of a confounding effect of species (see Additional File 1 for more information).

Mosquito mortality was modelled as a function of three factors; 'Age', 'Species' and 'Treatment'. The maximal model incorporating all factors, and including 'Family' as a random effect, is given in Table 3. There was evidence for an interaction between 'Age' and 'Treatment' $(\triangle \mathrm{AIC}=13.2$; Additional file 1$)$, however, mortality estimates are artificially inflated due to the addition of a small weighted constant in the zero cell group (younger mosquitoes exposed to LLIN\#1). Hence, to test for the affect of age, the GLMM omitting this interaction term is presented. A larger sample size would be required to improve estimates of the interaction between age and the LLIN tested. The criteria for selection of the fitted model $(\triangle \mathrm{AIC})$, estimated parameters, $z$ values and $p$ values are given in the Additional Information (Additional file 1).

According to the model, there was strong evidence that mosquito age had an effect on mortality. The older 


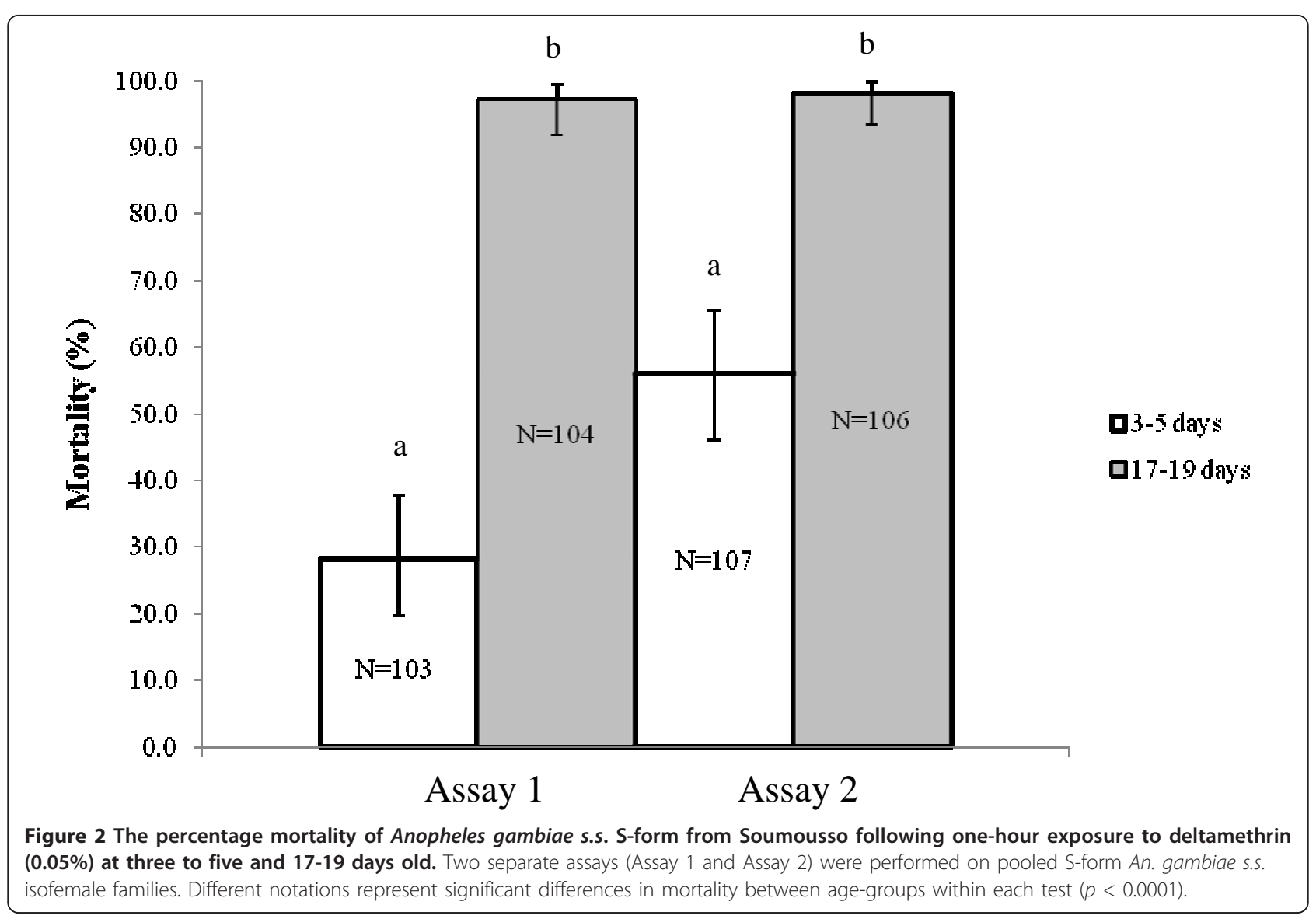

age group (17-19 days) were more likely to be killed on encountering the LLINs used in this experiment, compared with the younger cohort (three to five days) (Estimated OR $=5.28,95 \%$ CI 2.81-9.92, $\mathrm{p}<0.0001)$. It should be noted that this is a pooled estimate that assumes that the odds ratio is the same for each LLIN and species.

\section{Bendiocarb IRS assays}

To determine the susceptibility of An. gambiae s.s. to bendiocarb sprayed on the walls in Laye, three isofemale lines from Soumousso (An. gambiae s.s. M-form) were exposed in WHO cone tests for $30 \mathrm{~min}$. All mosquitoes were killed, suggesting complete susceptibility to bendiocarb from this area and this was confirmed in WHO susceptibility tests against both M- and S-form An. gambiae s.s. (mortality $100 \% 24 \mathrm{~h}$ after 1 hour exposure, $\mathrm{N}$ = 50 for $\mathrm{M}$-form, $\mathrm{N}=25$ for $\mathrm{S}$-form).

A total of 30 isofemale An. gambiae s.s. families from Soumousso (14 S-form, $3 \mathrm{M}$-form and $13 \mathrm{An}$. arabiensis) were exposed to bendiocarb sprayed walls at three to five days and 17-19 days old. The total number of mosquitoes exposed to each wall and the number dead per isofemale line are presented in Table 4. In order to estimate whether mosquito age had an effect on susceptibility, the exposure time was reduced to 3 minutes. There was no observed difference in mortality between any of the sprayed walls (Additional file 1) and as a result, 'Treatment' was dropped from the model. The final fitted model included 'Age' and 'Species' as fixed variables and the estimated parameters, $\mathrm{z}$-values and $\mathrm{p}$ values are presented in the Additional Information (Additional file 1).

There was strong evidence that the age had an effect on mortality and older mosquitoes (17-19 days) were more likely to be killed on exposure to the sprayed-walls used in this experiment $(\mathrm{OR}=3.39$, CI 95\% = 2.35-4.90). There was little evidence that the species status of the isofemale line had any effect on mortality rates (Table 3).

\section{Discussion}

Two findings with important implications for malaria control emerge from this study, one discouraging and the second potentially more positive. Firstly, LLINs selected for use in this study are not adequately killing malaria vectors. Secondly, malaria vectors become increasingly susceptible to insecticide exposure as they age. 
Table 1 Mortality within Anopheles gambiae s.l. isofemale lines exposed to LLINs collected from Laye village

\begin{tabular}{|c|c|c|c|c|c|c|c|c|}
\hline \multirow[b]{2}{*}{ Net } & \multirow[b]{2}{*}{ Family No. } & \multirow[b]{2}{*}{ Species* } & \multicolumn{3}{|c|}{ three to five days } & \multicolumn{3}{|c|}{ 17-19 days } \\
\hline & & & $\mathrm{N}$ & No. Dead & $\%$ Mortality & $\mathbf{N}$ & No. Dead & $\%$ Mortality \\
\hline \multirow[t]{12}{*}{ LLIN\#1 } & 1 & $S$ & 10 & 0 & 0.0 & 10 & 0 & 0.0 \\
\hline & 7 & $S$ & 10 & 0 & 0.0 & 11 & 4 & 36.4 \\
\hline & 15 & An. arabiensis & 9 & 0 & 0.0 & 9 & 3 & 33.3 \\
\hline & 39 & M & 11 & 0 & 0.0 & 10 & 0 & 0.0 \\
\hline & 44 & M & 10 & 0 & 0.0 & 11 & 1 & 9.1 \\
\hline & 104 & S & 10 & 0 & 0.0 & 10 & 0 & 0.0 \\
\hline & 149 & An. arabiensis & 10 & 0 & 0.0 & 9 & 5 & 55.6 \\
\hline & 208 & $M$ & 10 & 0 & 0.0 & 10 & 0 & 0.0 \\
\hline & 225 & M & 10 & 0 & 0.0 & 10 & 3 & 30.0 \\
\hline & 250 & M & 10 & 0 & 0.0 & 9 & 4 & 44.4 \\
\hline & 263 & M & 10 & 0 & 0.0 & 10 & 5 & 50.0 \\
\hline & 279 & M & 10 & 0 & 0.0 & 13 & 5 & 38.5 \\
\hline \multirow[t]{7}{*}{ LLIN\#2 } & 803 & $M$ & 11 & 0 & 0.0 & 11 & 4 & 36.4 \\
\hline & 815 & An. arabiensis & 11 & 4 & 36.4 & 11 & 11 & 100.0 \\
\hline & 843 & M & 9 & 5 & 55.6 & 10 & 5 & 50.0 \\
\hline & 858 & $M$ & 10 & 3 & 30.0 & 10 & 1 & 10.0 \\
\hline & 875 & An. arabiensis & 10 & 8 & 80.0 & 13 & 13 & 100.0 \\
\hline & 883 & An. arabiensis & 8 & 7 & 87.5 & 15 & 13 & 86.7 \\
\hline & 1062 & $S$ & 9 & 1 & 11.1 & 15 & 0 & 0.0 \\
\hline \multirow[t]{9}{*}{ LLIN\#3 } & 1156 & $S$ & 11 & 2 & 18.2 & 7 & 0 & 0.0 \\
\hline & 1157 & $S$ & 9 & 0 & 0.0 & 7 & 0 & 0.0 \\
\hline & 1165 & S & 9 & 1 & 11.1 & 7 & 1 & 14.3 \\
\hline & 1196 & $S$ & 11 & 0 & 0.0 & 5 & 0 & 0.0 \\
\hline & 1131 & $S$ & 10 & 0 & 0.0 & 10 & 1 & 10.0 \\
\hline & 1135 & $S$ & 9 & 0 & 0.0 & 8 & 0 & 0.0 \\
\hline & 1188 & $S$ & 11 & 0 & 0.0 & 10 & 0 & 0.0 \\
\hline & 1198 & $M$ & 10 & 0 & 0.0 & 9 & 1 & 11.1 \\
\hline & 1203 & S & 9 & 0 & 0.0 & 10 & 1 & 10.0 \\
\hline
\end{tabular}

${ }^{*} \mathrm{M}=$ An. gambiae s.s. $\mathrm{M}$-form; $\mathrm{S}=$ An. gambiae s.s. S-form

The poor performance of LLINs in the field highlights the importance of follow-up monitoring and evaluation after net distribution, particularly in areas where resistance may be further eroding net efficacy. This finding is, admittedly, based on a small sample size of three nets but these were selected at random from LLINs distributed by the NMCP in the past two years, i.e. well within the intended lifespan of the nets. No information on the number of washes is available but the insecticide concentration has decreased to equal or less than $4 \%$ of that of a new Permanet $2.0^{\circledR}$ and the mortality in the susceptible laboratory population is very low $(<53 \%)$ for two of the nets. For field populations from Burkina Faso, where resistance is prevalent, the mortality from the nets was disappointing when tested according to standard WHO procedures for assessing LLIN performance [30] (Figure 3).
Fortunately, as part of the NMCP of Burkina Faso, there are immediate plans to increase the number of houses covered with IRS to supplement the recent distribution of LLINs across the country. More than 118,000 people in the Diebougou district of south-west Burkina Faso have been protected through a recent IRS campaign [4]. Although the carbamate bendiocarb offers a promising alternative to pyrethroids, resistance has emerged in pockets of West Africa associated with the ace-1 mutation. In Burkina Faso, ace-1 is prevalent at moderate frequencies in An. gambiae s.s. from the south-west [14] and the introduction of bendiocarb for IRS in this region would represent an additional selection pressure on this mutation.

The second more positive finding is the main focus of this study. The results presented here confirm the findings from previous studies, which show a reduction in 


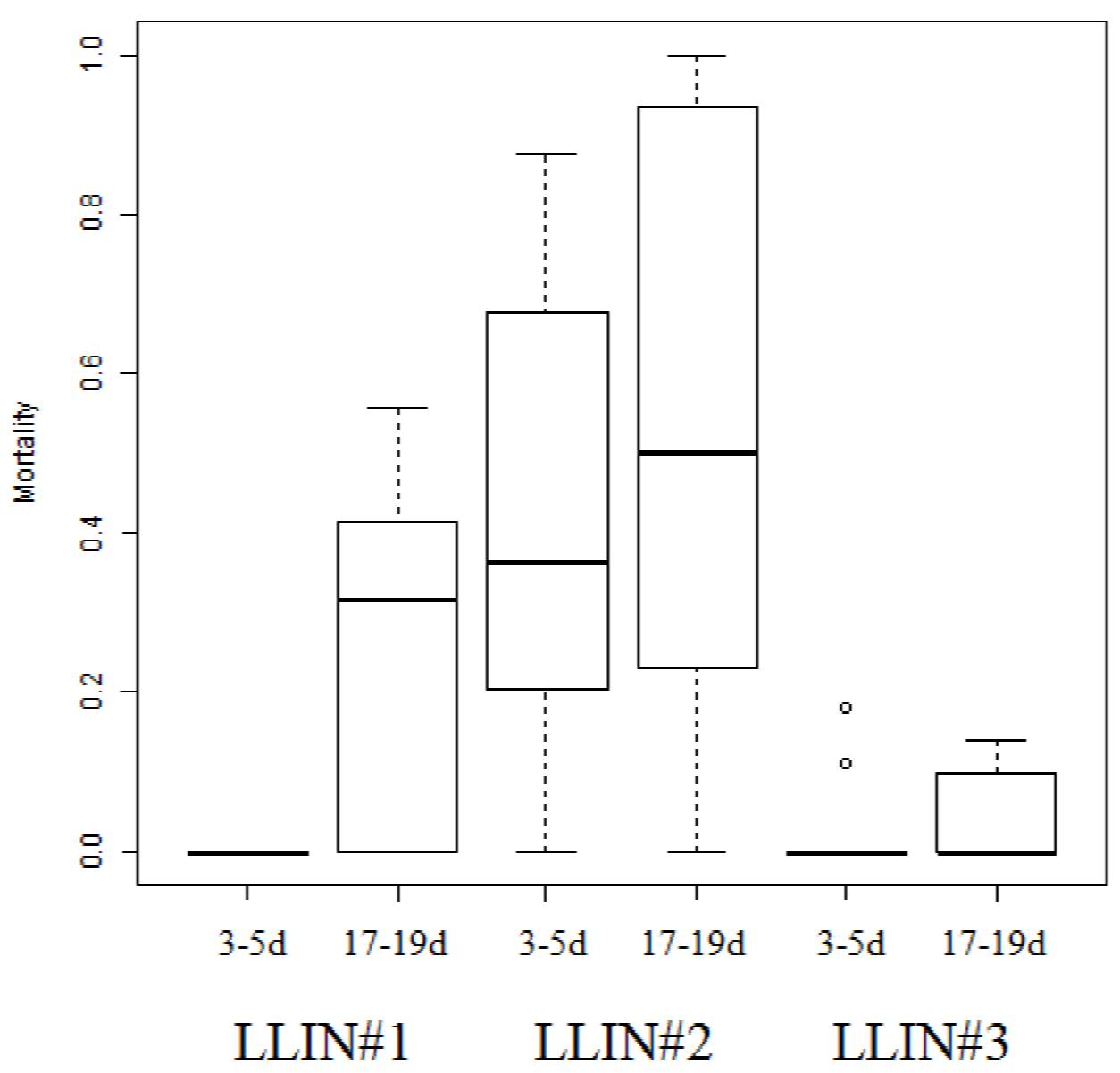

Figure 3 The mortality of isofemale Anopheles gambiae s.l. from Soumousso in response to LLINs from the field. The number of isofemale lines exposed to each net; LLIN\#1 = 12, LLIN\#2 = 7, LLIN\#3 = 9 .

phenotypic insecticide resistance in older mosquitoes [22-27]. The F1 progeny of An. gambiae s.s. S-forms collected from Soumousso were fully susceptible to deltamethrin (0.05\%) at 17-19 days old, despite being fully

Table 2 The percentage mortality of the laboratory susceptible Anopheles gambiae s.s. Kisumu strain exposed to LLINs from Laye for three minutes in a WHO cone bioassay, and the concentration of deltamethrin remaining on each net

\begin{tabular}{llllll}
\hline \multicolumn{4}{c}{ WHO Cone Bioassay } & & $\begin{array}{l}\text { Deltamethrin } \\
\text { concentration* }\end{array}$ \\
\hline LLIN & N & Dead & $\begin{array}{l}\text { Mortality } \\
\text { (\%) }\end{array}$ & Cl 95\% & $\mathbf{m g} / \mathrm{m}^{2}$ \\
\hline LLIN\#1 & 36 & 19 & 52.8 & $\begin{array}{l}35.5- \\
69.6\end{array}$ & 1.0 \\
\hline LLIN\#2 & 29 & 26 & 89.7 & $\begin{array}{l}72.7- \\
98.7\end{array}$ & 2.0 \\
\hline LLIN\#3 & 24 & 6 & 25.0 & $9.8-46.7$ & 1.9 \\
\hline
\end{tabular}

*determined using HPLC resistant at a younger age, according to WHO criteria (Figure 1). Earlier studies on this subject have focussed largely on laboratory colonies or have only been able to analyse a mixture of sub-species from the wild. The present study demonstrates that highly resistant insects from the field lose tolerance to insecticides at an older age.

When evaluated against either LLINs or sprayed walls in Burkina Faso, the potential operational impact of agedependent decreases in phenotypic resistance becomes evident. Nets that failed to kill young mosquitoes were still partially protective against older mosquitoes. Similarly, while bendiocarb IRS is currently effectively killing both age cohorts after a 30-min exposure, an age dependent effect is clearly visible after shorter exposures (Table 3).

A decrease in insecticide resistance with mosquito age may have significant epidemiological consequences for vector control in areas of wide LLIN and IRS coverage. The development of malaria parasites into the infectious sporozoite stage takes 10 or more days following a 
Table 3 The estimated effect of mosquito age, Anopheles gambiae s.l. species and treatment on mortality in isofemale lines in response to either LLINs or IRS

\begin{tabular}{|c|c|c|c|c|c|c|c|c|c|}
\hline & & $\mathrm{OR}^{*}$ & $95 \% \mathrm{Cl}^{\#}$ & $P$ value & & & OR & $95 \% \mathrm{Cl}$ & $P$ value \\
\hline $\mathrm{LLIN}^{\mathrm{a \lambda}}$ & & & & & $\mathrm{IRS}^{\mathrm{b}}$ & & & & \\
\hline \multirow[t]{3}{*}{ Age } & & & & & Age & & & & \\
\hline & Young (3-5d) & 1.00 & & & & Young (3-5d) & 1.00 & & \\
\hline & Old (17-19d) & 5.28 & 2.81-9.92 & $<0.0001$ & & Old (17-19d) & 3.39 & $2.35-4.90$ & $<0.0001$ \\
\hline \multirow[t]{4}{*}{ Species } & & & & & Species & & & & \\
\hline & An. arabiensis & 1.00 & & & & An. arabiensis & 1.00 & & \\
\hline & An. gambiae S-form & 0.04 & $0.01-0.19$ & $<0.0001$ & & An. gambiae S-form & 1.56 & $0.97-2.51$ & 0.065 \\
\hline & An. gambiae M-form & 0.13 & $0.04-0.43$ & 0.0007 & & An. gambiae M-form & 0.93 & $0.41-2.10$ & 0.855 \\
\hline \multicolumn{10}{|c|}{ Treatment } \\
\hline & LLIN\#1 & 1.00 & & & & & & & \\
\hline & LLIN\#2 & 5.58 & $2.97-10.5$ & 0.001 & & & & & \\
\hline & LLIN\#3 & 1.06 & $0.56-2.00$ & 0.987 & & & & & \\
\hline
\end{tabular}

IRS = indoor residual spraying; $L L I N=$ long-lasting insecticide net

${ }^{*} \mathrm{OR}=$ odds ratio

${ }^{\#} \mathrm{Cl}=$ confidence interval

${ }^{\lambda}$ Small weighted constant added to cells contributing to the zero cell count in the younger age-group for LLIN\#1

$\mathrm{a}=\mathrm{A}$ total of 28 isofemale lines were tested against three LLINs

$\mathrm{b}=\mathrm{A}$ total of 30 isofemale lines were exposed to three walls sprayed with bendiocarb $(0.1 \%)$

Table 4 Mortality within Anopheles gambiae s.l. isofemale lines exposed to bendiocarb-sprayed walls

\begin{tabular}{|c|c|c|c|c|c|c|c|c|}
\hline \multirow[b]{2}{*}{ WALL } & \multirow[b]{2}{*}{ Family No. } & \multirow[b]{2}{*}{ Species } & \multicolumn{3}{|c|}{ three to five days } & \multicolumn{3}{|c|}{ 17-19 days } \\
\hline & & & $\mathrm{N}$ & No. Dead & $\%$ Mortality & $\mathrm{N}$ & No. Dead & $\%$ Mortality \\
\hline \multirow[t]{10}{*}{ MUD\#1 } & 313 & M & 11 & 2 & 18.2 & 10 & 5 & 50.0 \\
\hline & 413 & An. arabiensis & 9 & 0 & 0.0 & 11 & 5 & 45.5 \\
\hline & 423 & An. arabiensis & 10 & 1 & 10.0 & 12 & 2 & 16.7 \\
\hline & 431 & An. arabiensis & 11 & 2 & 18.2 & 10 & 8 & 80.0 \\
\hline & 432 & An. arabiensis & 11 & 2 & 18.2 & 11 & 6 & 54.5 \\
\hline & 441 & An. arabiensis & 11 & 2 & 18.2 & 10 & 6 & 60.0 \\
\hline & 465 & An. arabiensis & 12 & 0 & 0.0 & 10 & 8 & 80.0 \\
\hline & 523 & $S$ & 11 & 4 & 36.4 & 8 & 3 & 37.5 \\
\hline & 528 & $S$ & 13 & 1 & 7.7 & 8 & 5 & 62.5 \\
\hline & 544 & $S$ & 12 & 0 & 0.0 & 8 & 4 & 50.0 \\
\hline \multirow[t]{10}{*}{ CEMENT\# 1} & 499 & $\mathrm{~S}$ & 10 & 3 & 30.0 & 8 & 4 & 50.0 \\
\hline & 537 & An. arabiensis & 11 & 2 & 18.2 & 9 & 5 & 55.6 \\
\hline & 557 & $\mathrm{~S}$ & 11 & 2 & 18.2 & 11 & 6 & 54.5 \\
\hline & 568 & An. arabiensis & 12 & 2 & 16.7 & 10 & 5 & 50.0 \\
\hline & 619 & $S$ & 11 & 3 & 27.3 & 10 & 2 & 20.0 \\
\hline & 631 & An. arabiensis & 9 & 2 & 22.2 & 10 & 7 & 70.0 \\
\hline & 637 & An. arabiensis & 12 & 2 & 16.7 & 9 & 5 & 55.6 \\
\hline & 663 & An. arabiensis & 12 & 0 & 0.0 & 7 & 1 & 14.3 \\
\hline & 685 & $S$ & 12 & 3 & 25.0 & 10 & 5 & 50.0 \\
\hline & 782 & $\mathrm{~S}$ & 10 & 1 & 10.0 & 10 & 5 & 50.0 \\
\hline \multirow[t]{5}{*}{ MUD\#2 } & 504 & An. arabiensis & 12 & 1 & 8.3 & 13 & 0 & 0.0 \\
\hline & 516 & An. arabiensis & 12 & 3 & 25.0 & 9 & 0 & 0.0 \\
\hline & 536 & $S$ & 12 & 5 & 41.7 & 10 & 3 & 30.0 \\
\hline & 551 & $S$ & 10 & 1 & 10.0 & 12 & 7 & 58.3 \\
\hline & 566 & S & 11 & 5 & 45.5 & 9 & 2 & 22.2 \\
\hline
\end{tabular}


Table 4 Mortality within Anopheles gambiae s.l. isofemale lines exposed to bendiocarb-sprayed walls (Continued)

\begin{tabular}{lllllllll}
\hline 569 & $M$ & 12 & 1 & 8.3 & 9 & 0 & 0.0 \\
\hline 609 & $M$ & 9 & 2 & 22.2 & 10 & 5 & 50.0 \\
\hline 680 & $S$ & 10 & 2 & 20.0 & 11 & 7 & 63.6 \\
\hline 754 & $S$ & 13 & 5 & 38.5 & 10 & 5 & 50.0 \\
\hline 768 & $S$ & 12 & 2 & 16.7 & 10 & 4 & 40.0 & \\
\hline
\end{tabular}

${ }^{*} \mathrm{M}=$ An. gambiae s.s. $\mathrm{M}$-form; $\mathrm{S}=$ An. gambiae s.s. S-form

blood-meal [35]. The older cohort of An. gambiae s.s. used in this study (17-19 days old) could potentially harbour infectious parasites but would be more susceptible to insecticide-based control. Targeting older, and arguably more epidemiologically significant mosquitoes, has been proposed as an alternative strategy for wider malaria control in which the selection on resistance to the control agent is reduced [36]. Natural senescence processes may contribute to the vulnerability of the older population in contact with any insecticide-based intervention. The importance of younger mosquitoes on the vectorial capacity should not, however, be overlooked, as the age at which a mosquito bites an infectious host is a key determinant on the potential to transmit the parasite to additional hosts [37]. The development of more advanced age-grading technologies offers the opportunity for further exploration of insecticide resistance in the context of the age-structure of local Anopheles vector populations [38].

It is widely assumed that mosquitoes possessing insecticide resistance traits will survive repeated exposures on encountering a LLIN or a sprayed house. Under this scenario, insecticide-based control efforts will fall short in reducing the mean population and more importantly, the mean survival rate of the vector, and as a result, fail to reduce the vectorial capacity below the threshold for disease control. There are, however, very few examples where a link between the presence of insecticide resistance and vector control failure has been demonstrated. If insecticide resistance and the associated mechanisms are so widespread amongst malarial vectors, why are vector control failures so few and far between? Part of the answer is undoubtedly that the appropriate experiments have not yet been performed to investigate the epidemiological impact of resistance. Studies extending over several transmission seasons that definitively demonstrate reduced survival of mosquitoes against insecticide-treated surfaces are very rare in the literature and this knowledge gap urgently needs to be filled.

\section{Additional material}

Additional File 1: Details the rationale and model parameters for the LLIN and IRS experiments and includes the following tables and figures. Table A1 The Akaike's Information Criteria (AIC) for model selection for the An. gambiae s.s. isofemale LLIN and IRS experiments. Table A2 The Akaike's Information Criteria (AIC) for model selection for the An. gambiae s.s. isofemale LLIN experiment excluding data for An. arabiensis. Table A3 Estimates of parameters, standard errors, 95\% confidence intervals, $z$ and $p$ values for mortality in response to LLINs. Table A4 Estimates of parameters, standard errors, 95\% confidence intervals, $z$ and $p$ values for mortality in response to bendiocarb-sprayed walls. Table A5 Individual estimates of parameters from re-fitted model with Age:Treatment interaction term for each treatment reference category. Figure A1 Mortality of isofemale lines in response to bendiocarb treated walls pooled by age.

\section{Acknowledgements}

The authors would like to thank the insectary and entomology team from CNRFP for their commitment to this project, which was pivotal to its success. They would also like to thank Pie Muller (Swiss Tropical and Public Health Institute) for statistical support as well as Mark Paine and Folasade Ajibade (LSTM) for the HPLC analysis. This project received financial support from BayerCrop Science and the UNICEF/UNDP/World Bank/WHO Special Programme for Research and Training in Tropical Diseases (WHO/TDR).

\section{Author details}

'Liverpool School of Tropical Medicine, Pembroke Place, Liverpool L3 5QA, UK. ${ }^{2}$ Centre National de Recherche et de la Formation sur Paludisme, 01 BP2208 Ouagadougou, Burkina Faso. ${ }^{3}$ Robertson Centre for Biostatistics, Boyd Orr Building, University of Glasgow, Glasgow G12 8QQ, UK.

\section{Authors' contributions}

HR and SN conceived the study. All authors participated in the study design. $\mathrm{CJ}$ and AS oversaw field collections, bioassays and conducted laboratory work. CJ wrote a draft of the manuscript. CJ and PCDJ performed the statistical analysis. All authors read and approved the final manuscript.

\section{Competing interests}

This work was partially funded by BayerCropScience and they provided the bendiocarb for the IRS. BayerCropScience played no role in the experimental design or interpretation of the results.

Received: 20 September 2011 Accepted: 23 January 2012 Published: 23 January 2012

\section{References}

1. Lengeler C: Insecticide-treated bed nets and curtains for preventing malaria. Cochrane Database of Systematic Reviews 2004, CD000363.

2. Kleinschmidt I, Schwabe C, Shiva M, Segura JL, Sima V, Mabunda SJA, Coleman M: Combining indoor residual spraying and insecticide-treated net interventions. AmJTrop Med Hyg 2009, 81:519-524.

3. Pluess B, Tanser FC, Lengeler C, B S: Indoor residual spraying for preventing malaria. Cochrane Database of Systematic Reviews 2010, CD006657.

4. President's Malaria Initiative: Fifth Annual Report to Congress. Washington: D. C 2011.

5. WHO: Global Malaria Action Plan World Health Organization; 2009.

6. Konaté AT, Yaro JB, Ouedraogo AZ, Diarra A, Gansane A, Soulama I, Kangoyé DT, Kabore $Y$, Ouedraogo E, Ouedraogo A, Tiono AB, Ouédraogo IN, Chandramohan D, Cousens S, Milligan PJ, Sirima SB, 
Greenwood B, Diallo DA: Intermittent preventive treatment of malaria provides substantial protection against malaria in children already protected by an insecticide-treated bednet in Burkina Faso: a randomised, double-blind, placebo-controlled trial. PLOS Med 2011, 8 : e23391.

7. Santolamazza F, Calzetta M, Etang J, Barrese E, Dia I, Caccone A, Donnelly MJ, Petrarca V, Simard F, Pinto J, Della Torre A: Distribution of knock-down resistance mutations in Anopheles gambiae molecular forms in west and west-central Africa. Malar J 2008, 7:74.

8. Ranson H, N'Guessan R, Lines J, Moiroux N, Nkuni Z, Corbel V: Pyrethroid resistance in African anopheline mosquitoes: what are the implications for malaria control? Trends Parasitol 2011, 27:91-98.

9. Hargreaves K, Koekemoer LL, Brooke BD, Hunt RH, Mthembu J, Coetzee M Anopheles funestus resistant to pyrethroid insecticides in South Africa. Med Vet Ent 2000, 14:181-189.

10. Munhenga G, Masendu HT, Brooke BD, Hunt RH, Koekemoer LK: Pyrethroid resistance in the major malaria vector Anopheles arabiensis from Gwave, a malaria-endemic area in Zimbabwe. Malar J 2008, 7:247.

11. Akogbeto MC, Padonou GG, Gbenou D, Irish S, Yadouleton A: Bendiocarb, a potential alternative against pyrethroid resistant Anopheles gambiae in Benin. West Africa Malar J 2010, 9:204

12. N'Guessan R, Boko P, Odjo A, Chabi J, Akogbeto M, Rowland M: Control of pyrethroid and DDT-resistant Anopheles gambiae by application of indoor residual spraying or mosquito nets treated with a long-lasting organophosphate insecticide, chlorpyrifos-methyl. Malar J 2010, 9:44.

13. Alou LPA, Koffi AA, Adja MA, Tia E, Kouassi PK, Kone M, Chandre F: Distribution of ace-1(R) and resistance to carbamates and organophosphates in Anopheles gambiae s.s. populations from Cote d'Ivoire. Malar J 2010, 9:167.

14. Dabire KR, Diabate A, Namontougou M, Djogbenou L, Kengne P, Simard F, Bass C, Baldet T: Distribution of insensitive acetylcholinesterase (ace-1(R)) in Anopheles gambiae s.l. populations from Burkina Faso (West Africa). Trop Med Int Health 2009, 14:396-403.

15. Zaim M, Guillet P: Alternative insecticides: an urgent need. Trends Parasitol 2002, 18:161-163.

16. Kelly-Hope L, Ranson H, Hemingway J: Lessons from the past: managing insecticide resistance in malaria control and eradication programmes. Lancet Infect Dis 2008, 8:387-389.

17. Hemingway J, Beaty BJ, Rowland M, Scott TW, Sharp BL: The innovative vector control consortium: improved control of mosquito-borne diseases. Trends Parasitol 2006, 22:308-312.

18. Diabate A, Baldet T, Chandre F, Akogbeto M, Guiguemde TR, Darriet F, Brengues C, Guillet P, Hemingway J, Small GJ, et al: The role of agricultural use of insecticides in resistance to pyrethroids in Anopheles gambiae s.l. in Burkina Faso. AmJTrop Med Hyg 2002, 67:617-622.

19. Dabire KR, Diabate A, Namountougou M, Toe KH, Ouari A, Kengne P, Bass C, Baldet T: Distribution of pyrethroid and DDT resistance and the L1014F kdr mutation in Anopheles gambiae s.l. from Burkina Faso (West Africa). Trans R Soc Trop Med Hyg 2009, 103:1113-1120.

20. Ranson H, Abdallah H, Badolo A, Guelbeogo WM, Kerah-Hinzoumbe C, Yangalbe-Kalnone E, Sagnon N, Simard F, Coetzee M: Insecticide resistance in Anopheles gambiae: data from the first year of a multi-country study highlight the extent of the problem. Malar J 2009, 8:299.

21. Rivero A, Vezilier J, Weill M, Read AF, Gandon S: Insecticide Control of Vector-Borne Diseases: When Is Insecticide Resistance a Problem? PLoS Pathogens 2010, 6.

22. Rowland $\mathrm{M}$, Hemingway $\mathrm{J}$ : Changes in malathion resistance with age in Anopheles stephensi from Pakistan. Pest Biochem Phys 1987, 28:239-247.

23. Lines JD, Nassor NS: DDT resistance in Anopheles gambiae declines with mosquito age. Med Vet Ent 1991, 5:261-265.

24. Hodjati $\mathrm{MH}$, Curtis CF: Evaluation of the effect of mosquito age and prior exposure to insecticide on pyrethroid tolerance in Anopheles mosquitoes (Diptera: Culicidae). Bull Ent Res 1999, 89:329-337.

25. Rajatileka S, Burhani J, Ranson H: Mosquito age and susceptibility to insecticides. Trans R SocTrop Med Hyg 2011, 105:247-253.

26. Glunt KD, Thomas MB, Read AF: The effects of age, exposure history and malaria infection on the susceptibility of Anopheles mosquitoes to low concentrations of Pyrethroid. PLoS One 2011, 6.

27. Hunt RH, Brooke BD, Pillay C, Koekemoer LL, Coetzee M: Laboratory selection for and characteristics of pyrethroid resistance in the malaria vector Anopheles funestus. Med Vet Ent 2005, 19:271-275.
28. Santolamazza F, Mancini E, Simard F, Qi YM, Tu ZJ, della Torre A: Insertion polymorphisms of SINE200 retrotransposons within speciation islands of Anopheles gambiae molecular forms. Malar J 2008, 7:163.

29. Bass C, Nikou D, Donnelly MJ, Williamson MS, Ranson H, Ball A, Vontas J, Field LM: Detection of knockdown resistance $(\mathrm{kdr})$ mutations in Anopheles gambiae: a comparison of two new high-throughput assays with existing methods. Malar J 2007, 6:111.

30. WHO: Test procedures for insecticide resistance monitoring in malaria vectors, bio-efficacy and persistence of insecticides on treated surfaces World Health Organization; 1998

31. R: A language and environment for statistical computing. R Foundation for Statistical Computing Vienna: Austria; 2011.

32. Bates DM: M: Ime4. Linear mixed-effects models using S4 classes. $R$ package version 0.999375-35 2010

33. Agresti A: An Introduction to Categorical Data Analysis New York: Wiley; 1996.

34. Anderson DR, Burnham KP, Thompson WL: Null hypothesis testing problems, prevalence, and an alternative. J Wildl Manag 2000, 64:912-923.

35. Beier JC: Malaria parasite development in mosquitoes. Ann Rev Ent 1998, 43:519-543.

36. Read AF, Lynch PA, Thomas MB: How to make evolution-proof insecticides for malaria control. PLOS Biol 2009, 7:e1000058.

37. Styer LM, Carey JR, Wang J-L, Scott TW: Mosquitoes do senesce: departure from the paradigm of constant mortality. AmJTrop Med Hyg 2007, 76:111-117.

38. Sikulu M, Killeen GF, Hugo LE, Ryan PA, Dowell KM, Wirtz RA, Moore SJ, Dowell FE: Near-infrared spectroscopy as a complementary age grading and species identification tool for African malaria vectors. Parasit Vectors 2010, 3:49.

doi:10.1186/1475-2875-11-24

Cite this article as: Jones et al:: Aging partially restores the efficacy of malaria vector control in insecticide-resistant populations of Anopheles gambiae s.l. from Burkina Faso. Malaria Journal 2012 11:24.

\section{Submit your next manuscript to BioMed Central and take full advantage of:}

- Convenient online submission

- Thorough peer review

- No space constraints or color figure charges

- Immediate publication on acceptance

- Inclusion in PubMed, CAS, Scopus and Google Scholar

- Research which is freely available for redistribution

Submit your manuscript at www.biomedcentral.com/submit
C Biomed Central 